Name: Caroline Elisse

NRP : 130318222

Kelas Paralel : A

No Urut : 66

\title{
THE IMPLEMENTATION OF GCG IN INDONESIAN COMPANIES IN THE ERA OF ECONOMIC DISRUPTION
}

\begin{abstract}
Carrying out business and human resource transformation, changing business concepts that are driven and patterned by the increasing advancement of information technology. Economic disruption conditions require companies in Indonesia to generate new values in all aspects so that the company's performance increases and the company is able to survive in the market by obtaining maximum profits. Human resource management is also important, especially if there is an employee engagement in dealing with threats originating from the external environment. Research used to overcome global economic disruptions is qualitative research with an interpretive paradigm based on the reality or phenomena that occur.
\end{abstract}

\section{INTRODUCTION}

Global economic conditions in 2018, with the existence of high global financial uncertainty, are considered to have unbalanced economic conditions and even sluggishness which may occur due to worsening trade relations between countries resulting in low volume of world trade. Business people in Indonesia are required to constantly update, innovate and create diversification in order to be able to compete with competitors in the world market in the era of economic disruption until 2020 by optimizing the strategies that have been determined to obtain maximum benefits. From 2016 to 2018, the Company strives to show its respective advantages with the hope that the business will experience rapid development even though it is in conditions of intense business competition. Companies are always faced with a drastically changing business environment supported by advances in digital technology, changes in socio-political conditions and the presence of new markets, causing old companies to try to make adjustments by creating changes by transforming business and resources and being able to adapt to the Industrial Revolution. 4.0. Company management can build governance systems and mechanisms that lead and control the transformation of company resources to create added value in realizing sustainable competitiveness. Therefore, companies are required to implement Good Corporate Governance (GCG) with good quality so as to enable the creation of added value for company stakeholders which in the long term is beneficial for the business, namely sustainable business success. The implementation of GCG is considered effective if it is implemented by the company because the 
company will get many benefits, such as ensuring the formation of a corporate culture, information disclosure, triggering the effectiveness of the audit system performance, and risk control which refers to the GCG standards. The implementation of GCG is able to raise awareness, socialize the code of ethics and implement GCG standards, assess GCG, The need for GCG, full openness and full transparency and an action plan so that this has an impact on meeting the needs of the company in a clear framework so that the direction of the organization can be clear and measurable, and the implementation of strategies is appropriate and sustainable so that it is in accordance with the vision and mission that has been set together.

\section{RESEARCH METHOD}

The case of global economic disruption uses research in the qualitative category with an interpretive paradigm which aims to analyze the reality of global economic uncertainty and fluctuations in the exchange rate of the rupiah against the US dollar. In addition, research with an interpretive approach is expected to determine the effect of global economic uncertainty and currency exchange rate fluctuations on the life of companies in Indonesia so that Indonesian companies can survive in the face of global business competition. This case research was conducted by examining the phenomena and methods used in the study. Then proceed with the activity of interpreting the findings.

\section{RESULTS AND DISCUSSION}

The use of high technology has an aggressive tendency in opening new workforce recruitments so that this is closely related to the industrial sector and the mining sector. Companies must be selective in recruiting new workers because of increasingly fierce business competition which results in companies having to look for highly competent workers with data analysis and business intelligence skills, digital-based marketing and software programming skills. Thus, the development of the digital economy encourages the search for new workers who always prioritize information technology skills. Fast-moving digital technology requires companies to change their skills, given the skills that workers have, so new competencies are needed. In the face of economic disruption and industrial revolution 4.0, it depends on the ability to take advantage of change in line with the advancement of changing technology that continues to increase in order to survive, develop, and provide significant added value for all stakeholders. The organization must try to predict its future conditions in a clear framework so that the vision and mission of the organization is clear and measurable and the implementation of strategies is right on target. To achieve the vision, mission and goals of the organization, the company needs a strategy. However, in carrying out a new strategy in the company requires an organizational preparation in aligning the strategy carried out with the business processes carried out within the organization, organizational structure, human resource competence, and culture so that a self-assessment system is needed to identify and implement strategies with existing processes so that the company is able to direct and achieve alignment of the company's adjustment process. The trends of globalization, digitization and trade wars have made the world experience volatility, uncertainty, complexity and ambiguity 
(VUCA) so that companies are required to make changes by carrying out business transformation and human resource transformation. Companies that successfully carry out business activities and transform human resources are PT. BNI, Tbk. and PT. Hartono Plantation Indonesia (HPI-Agro). Transformation can be carried out from the aspects of strategy, systems, management, organization, information technology, human resources, and funding. The existing transformation process must meet the basic principles of GCG, transparency, accountability, responsibility, independence, and fairness. The implementation of GCG is able to encourage aspects of openness, accountability and trust. In addition, the implementation of GCG assists companies in empowering functions in business units and increasing the independence of company organs which has a significant impact on the progress of the company. Companies that implement the GCG system are required to continue to strive to create and introduce new values in the aspects of products, operations and services that have an impact on improving company performance that benefits stakeholders. In producing superior performance, it requires the effectiveness of the organizational structure which is influenced by the quality of leadership and the applied management system.

\section{CONCLUSION}

In facing economic disruption, companies in Indonesia must create competitive advantages through transformation at all levels and business units operated as well as continuous innovation in order to survive in the domestic and global market. Company leaders must strive to face a future full of volatility, uncertainty, complexity, and ambiguity (VUCA). Performance targets should be lowered from the top level to the individual so that each employee can move in the same direction. In addition, employees must be able to foster shared values in each employee and become role models for all employees. The implementation of GCG in companies is proven to be able to increase company value, market value, cultural value, information disclosure, audit system effectiveness, and risk control.

\section{REFERENCE}

Dessler, G. 2005. Human Resources Development. Tenth Edition. New Jersey: Prentice Hall. Effendi MA 2009. The Power of Good Corporate Governance: Theory and Implementation Jakarta: Salemba Empat.

Hitt, MA Ireland, RD \& Hoskisson, RE2001. "Strategic Management: Concepts: Competitiveness and Globalization", 4th Edition. Stamford USA: Cengage Learning 